\title{
REESTRUTURAÇÃO ECONÔMICA E URBANA EM UMA CIDADE MÉDIA DO SEMIÁRIDO BRASILEIRO
}

\author{
economical and urban restructuring in a medium size city of the brazilian semi-arid
}

\author{
Denise Elias ${ }^{1}$ \\ Renato Pequeno ${ }^{2}$ \\ ${ }_{a} a \boldsymbol{a a}_{a}$
}

\begin{abstract}
Resumo
Com a expansão dos sistemas de objetos e sistemas de ação voltados a dotar o território brasileiro de fluidez para os investimentos produtivos, muitos lugares que, do ponto de vista da divisão internacional do trabalho, compunham o exército de lugares de reserva, tornam-se atrativos à produção globalizada e são incorporados aos circuitos produtivos de empresas nacionais e multinacionais hegemônicas em diferentes ramos da economia. Diante das novas características advindas com as reestruturações econômicas e territoriais no Brasil, os antigos esquemas utilizados para classificar a sua rede urbana, as divisões regionais, pensar a hierarquia urbana necessitam de uma revisão que dê conta da complexidade da realidade atual. Os estudos sobre a os espaços urbanos não metropolitanos em diferentes regiões do país representam um dos caminhos necessários para avançar na compreensão da complexidade da realidade brasileira contemporânea.
\end{abstract}

Palavras-chave: Reestruturação urbana e regional, Urbanização dispersa, Cidade média, Mossoró

\begin{abstract}
Due to the expansion of the system of objects and system of actions developed for providing the Brazilian territory of fluidity for the productive investments, it happens the decentralization of the production, specially since the 1980s. In this context, many places, considering the international division of labour and composed the reserve army of places, become more attractive to the globalized production being incorporated to the productive circuits of national and multi-national enterprises, which are hegemonic at different economic branches. Hereby, it increases the territorial division of labour and the inter-sectorial exchanges, resulting in urban and regional restructuring of several natures and magnitudes over all the national territory. In the presence of new characteristics occurred with the economic and territorial restructuring in Brazil, the old schemes used for classify its urban network, establish the regional division and think about the urban hierarchy need to be reviewed in order to be enough to attend the complexity of existing reality. The studies about the non-metropolitan urban spaces at different regions in Brazil represent one of the ways to improve the comprehension of the contemporary Brazilian complexity. This article presents some results of a collective research developed in network.
\end{abstract}

Key words: Urban and regional restructuring, New economic agents, Disperse urbanization, Medium size city, Mossoró.

\section{Résumé}

Avec l'expansion des systèmes d'objets et des systèmes d'action visant à doter le territoire brésilien d'une fluidité pour les investissements productifs, de nombreux lieux qui, du point de vue de la division internationale du travail, composaient une armée d'endroits de réserve, deviennent attractifs à la production mondialisée et sont ainsi incorporés dans les circuits productifs d'entreprises nationales et de multinationales hégémoniques dans les différentes branches de l'économie. En face de ces nouvelles caractéristiques venues avec les restructurations économiques et territoriales du Brésil, les anciens schémas utilisés pour classifier son réseau urbain, les divisions régionales et penser à la hiérarchie urbaine demande une révision qui prend en compte la complexité de la réalité actuelle. Les études sur les espaces urbains non métropolitains dans différentes régions du Brésil représentent un des chemins nécessaires pour avancer dans la compréhension de la complexité de la réalité contemporaine.

Mots-clé: Restructuration urbaine et régionale, Urbanisation disperse, Ville moyenne, Mossoró.

(1) Bolsista Produtividade do CNPq, Prof ${ }^{a}$. Dr ${ }^{a}$. do Programa de Pós-Graduação em Geografia da Universidqade Eatadual do Ceará - Av. Paranjana, CEP: 60740-000, Fortaleza (CE), Brasil, Tel: (+55 85)35211170 - deniselias@uol.com.br

(2) Prof. Dr. do Programa de Pós-Graduação em Geografia da Universidade Federal do Ceará - Avenida da Unniversidade, 2890, CEP: 60020-181, Fortaleza (CE), Brasil, Tel: (+55 85) 33667491 - luisrenatobp@uol.com.br

\section{aaAa}




\section{INTRODUÇÃO}

Com a expansão dos sistemas de objetos voltados a dotar o território brasileiro de fluidez para os investimentos produtivos, ocorre uma descentralização da produção. Nesse contexto, até a década de 1980, muitos lugares que, do ponto de vista da divisão internacional do trabalho, compunham o que Santos (1993) chamou de 'exército de lugares de reserva', tornam-se atrativos à produção moderna e são incorporados aos circuitos produtivos globalizados de empresas nacionais e multinacionais hegemônicas em diferentes ramos da economia. Acirra-se, assim, a divisão territorial do trabalho e as trocas intersetoriais, resultando em reestruturações urbanas e regionais de várias naturezas e magnitudes por todo o território nacional.

Diante das novas características econômicas e territoriais do Brasil, os antigos esquemas utilizados para classificar a sua rede urbana, as divisões regionais, as regiões metropolitanas, a hierarquia urbana necessitam de uma revisão que dê conta da complexidade da realidade atual. Os estudos sobre os espaços urbanos não metropolitanos que apresentam grande dinamismo econômico, em diferentes regiões do país, representam um dos caminhos necessários para avançar na compreensão da complexidade da realidade brasileira contemporânea. Com a generalização do fenômeno da urbanização da sociedade e do território que o Brasil atinge no final do século XX, os trabalhos de investigação científica sobre esses espaços em tais condições têm sua relevância reforçada.

Entre as partes do Brasil recentemente incorporadas aos circuitos produtivos globalizados de grandes empresas, nacionais e multinacionais, hegemônicas em diferentes ramos da economia, destacaremos nesse texto um exemplo no Semiárido brasileiro que, na sua maior parte, permaneceu como lugar de reserva, à margem de tais circuitos até pouco tempo. Mas, que nas últimas três décadas, de forma intensa, assume novos papéis na divisão territorial do trabalho em diferentes escalas e passa a ter ramos econômicos inseridos à dinâmica da produção moderna e vive, desde então, importantes transformações socioespaciais.

Mossoró, com perto de 260 mil habitantes, segunda principal cidade do Estado do Rio Grande do Norte, localizada entre as capitais Fortaleza (CE) e Natal (RN), e ampla região sob sua influência, estão entre as novas áreas economicamente dinâmicas do Brasil, nas quais é possível observar as transformações na produção que se processa, cada vez mais, com utilização intensiva de capital, tecnologia e informação, principais forças produtivas do presente período histórico, sendo visível a substituição crescente do meio natural e do meio técnico pelo meio técnico-científico-informacional (SANTOS, 1988, 1996), que tem resultado em processos de reestruturação urbana e regional. Entre nossas principais preocupações na pesquisa realizada que dá origem ao presente texto, está justamente compreender a economia política dessa urbanização, especialmente a partir dos novos agentes econômicos.

De acordo com o Instituto Brasileiro de Geografia e Estatística (IBGE, 2008), Mossoró possui uma área de influência com algo próximo a 650 mil habitantes, composta por 39 municípios, localizados no mesmo Estado, o que representa mais de $21 \%$ do total da população potiguar. Deve também ser mencionado que outros municípios, mesmo sem fazer parte da região de influência de Mossoró segundo os critérios adotados pelo IBGE, possuem relações de cunho comercial e de prestação de serviços, como é o caso dos municípios da região do Baixo Jaguaribe, no Ceará, fortemente associados a Mossoró em função do agronegócio da fruticultura, e os municípios do litoral leste cearense, tais como Aracati e Icapuí, onde a exploração do petróleo é comandada a partir da base da Petrobras situada em Mossoró, evidenciando que entre esses espaços complexificam-se as teias formadas pelos círculos de cooperação e circuitos espaciais da produção das respectivas atividades. Ainda de acordo com a Regic, a rede urbana composta por municípios sob a influência de Mossoró organiza-se em quatro níveis: Mossoró como capital regional; Açu, como subcentro regional; Apodi, Patu e Umarizal como centros de zona e todas as demais como centros locais.

Quando da difusão de inovações e da descentralização da produção moderna no Brasil, Mossoró mostrou-se um espaço propício para o seu exercício, dada sua baixa presença de rugosidades 
(SANTOS, 1988) e pouca resistência aos capitais externos. Rapidamente, tornou-se um lócus de expansão de novos capitais, permitindo que tanto esses quanto as práticas hegemônicas da produção moderna se disseminassem rapidamente e substituíssem parte das formas tradicionais de produção, dificultando uma regulação local e a ação de empresas menos competitivas.

$\mathrm{Na}$ área de influência de Mossoró, realiza-se parte dos circuitos espaciais da produção e círculos de cooperação (SANTOS, 1986) de três importantes atividades econômicas, hoje hegemônicas na organização do espaço urbano e rural do município e região, que apresentam destacado dinamismo e juntas são responsáveis por parte do crescimento urbano desse município e por significativas outras reestruturações. Trata-se da extração e beneficiamento de sal; do agronegócio da fruticultura tropical (especialmente melão e banana) e da exploração do petróleo e do gás natural. Mossoró concentra a quase totalidade da extração de sal do país, assim como é o principal produtor brasileiro de melão, voltado, em grande parte, à exportação para a Europa e Estados Unidos, assim como é hoje o primeiro produtor brasileiro de petróleo com exploração em terra e o segundo em volume geral (terra e mar).

Uma especificidade muito importante de Mossoró é a de que o que existe de moderno é totalmente baseado nas velhas formas de apropriação da natureza, ou seja, as três atividades produtivas pilares da economia da cidade e área sob sua influência são baseadas na apropriação da natureza, transformando fatores naturais em mercadorias, em especial: 1) um recurso natural que vem da água do mar: o sal; 2) um mineral e fonte de energia, no caso de Mossoró, especialmente extraído da terra e do mar: o petróleo e gás natural; 3) a terra agrícola, a partir da qual, no caso, se produz frutas tropicais.

Dessa forma, grande parte da economia de Mossoró e sua área de influência estão baseadas na apropriação privada de alguns importantes recursos naturais e na transformação dos mesmos em mercadorias. Isso é determinante para o estabelecimento do preço final, pois significa que as empresas atuantes nas respectivas atividades auferem, além de rendas absolutas, também rendas diferenciais e de monopólio.

Uma outra especificidade totalmente inerente à anterior diz respeito ao fato de que, na sua grande maioria, os territórios produtivos do sal, do petróleo e da fruticultura encontram-se somente numa pequena parte no município de Mossoró, uma vez que a maior parte se encontra no seu entorno, parte, inclusive, em outro Estado (CE). Mas, no espaço urbano de Mossoró passam todos os circuitos locais e regionais de produção dessas três atividades produtivas, que se conectam permanentemente com outras partes do mundo, sendo nítidos os rebatimentos na economia e no território. Tudo isso tem resultado, entre outros impactos, em mudanças na estrutura fundiária, em transformações nas relações de trabalho, na economia urbana e modificações nos padrões de urbanização, sendo notável, a reestruturação urbana.

A figura 1 reúne o conjunto dos territórios produtivos, associados às principais atividades econômicas, destacando-se que os mesmos avançam, para o vizinho Estado do Ceará, no que se refere à extração do petróleo e ao agronegócio da fruticultura tropical.

A presença de atividades distintas que diversificam a economia local/regional faz da cidade que organiza esse espaço o lócus da presença de diferentes processos, os quais ampliam a complexidade do espaço intra-urbano de Mossoró.

Consideramos importante mencionar a evolução da população total, urbana e da taxa de urbanização de Mossoró. Os dados relativos à população total do município dão-nos um contingente de cerca de 97 mil habitantes em 1970 e de cerca de 260 mil habitantes em 2010, de acordo com dados do IBGE (2010). A população urbana, por sua vez, passou de pouco mais de 79 mil para mais de 237 mil habitantes no mesmo período, evidenciando que o crescimento da população urbana é mais acelerado do que o da população total, tendo crescido cerca de três vezes no período.

Este artigo busca discutir o quadro de dinâmicas urbanas contemporâneas associadas à presença de novos agentes econômicos, notadamente do setor terciário relacionados às atividades produtivas 
supra-mencionadas, assim como inerentes ao crescimento populacional. Justifica-se tal abordagem pelo fato de que na cidade se realiza boa parte do consumo produtivo vinculado à salinicultura, à extração do petróleo e à fruticultura, mesclando-se ao consumo consumptivo.
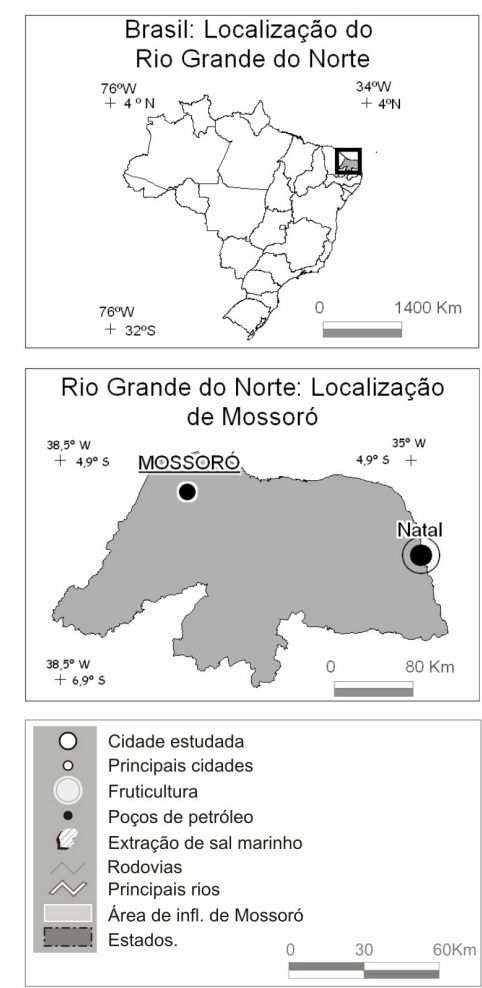

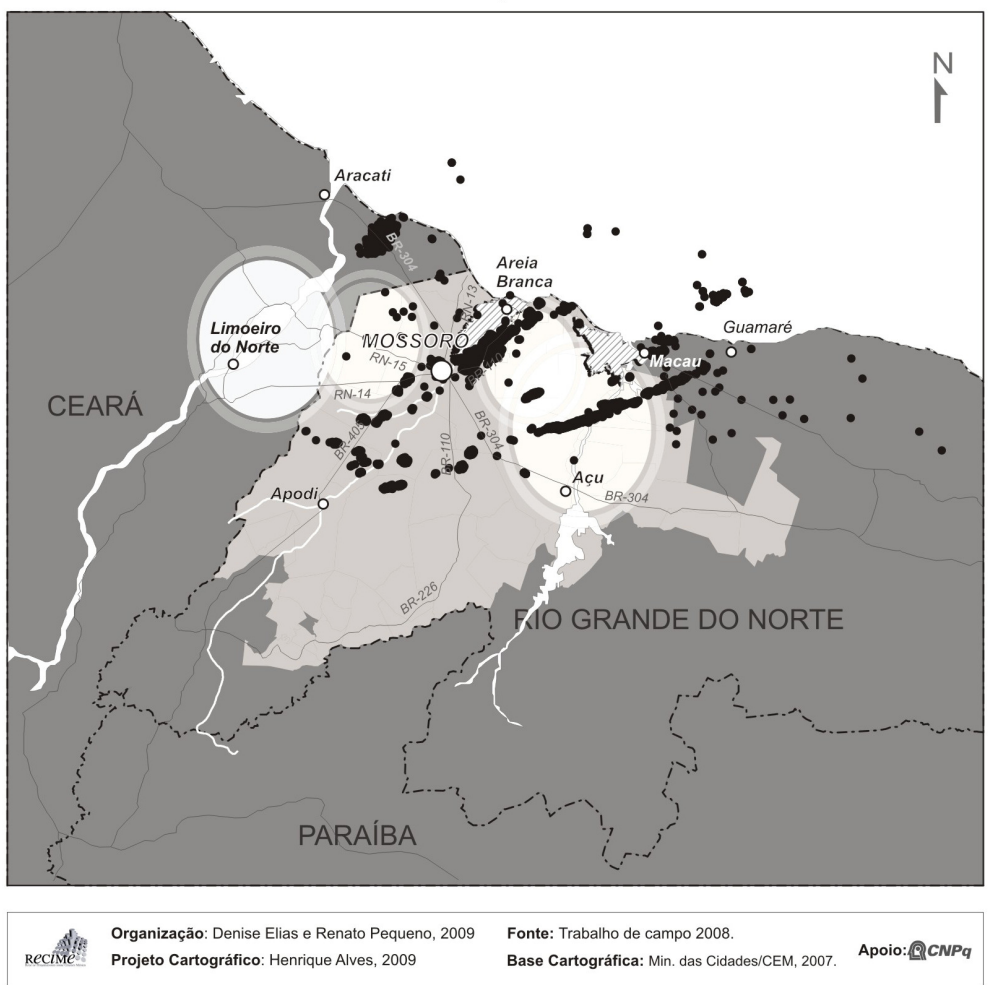

Figura 1 - Mossoró e região. Territórios produtivos da fruticultura, do sal e do petróleo. 2008.

\section{DIFUSÃO DE NOVOS AGENTES ECONÔMICOS NO COMÉRCIO E SERVIÇOS}

O comércio e os serviços desempenham importante papel para buscarmos compreender como se processa a expansão da economia e da estrutura urbana de Mossoró. Além de evidenciar muitos tipos de fluxos de pessoas, de matérias-primas e de mercadorias, o crescimento do terciário serve de guia para essa análise. A expansão do terciário é devida, em parte, ao crescimento populacional e à revolução do consumo, erigida sob os auspícios do consumo de massa, associadas à existência individual e das famílias. Por outro lado, as próprias demandas das atividades produtivas fazem crescer uma série de comércios e serviços especializados, fazendo aumentar também o consumo produtivo (Elias, 2003).

O dinamismo das três principais atividades econômicas da região polarizada por Mossoró contribui para a elevação da média salarial e da renda, principalmente dos trabalhadores especializados associados aos respectivos ramos, expandindo a classe média. Isso acaba por propiciar o surgimento de um número de casas de comércio e de estabelecimentos que oferecem serviços especializados, alguns bastante modernos, antes restritos às principais metrópoles do país.

Nessas condições, vem aumentando o consumo produtivo e consumptivo, de bens duráveis e não duráveis, e de uma série de outras atividades que se enquadram dentro do terciário, o que pode ser observado, por exemplo, através da implantação de ramos de atividades econômicas representativas da atuação dos novos agentes econômicos.

Entre esses poderíamos citar a implantação de serviços de saúde especializados; de agências bancárias, incluindo de bancos privados; de serviços de educação superior; de redes de venda de eletrodomésticos e eletrônicos; de empresas do setor imobiliário; de supermercados e hipermercados; de lojas de departamento; de franquias nacionais e multinacionais; de serviços de transporte 
de carga, de segurança etc. Tudo isso multiplicou e tornou mais complexos os fixos e os fluxos (Santos, 1988) em Mossoró e região, que vêm reorganizando sua estruturação urbana e regional.

Poderíamos exemplificar com o ramo de supermercados. Até o segundo semestre de 2008, Mossoró caracterizava-se por apresentar um ramo de supermercados sem nenhum investimento de capital nacional ou multinacional, sendo todos os empreendimentos existentes de capital local ou regional.

Considerando somente os estabelecimentos que mais diretamente interessavam à nossa pesquisa, ou seja, pelo porte e abrangência do mercado, destacaríamos duas redes como as principais em atuação na cidade, ambas instaladas a partir da década de 1990: Queiroz e Rebouças. A primeira possui seis lojas em Mossoró, além de três em cidades vizinhas (Apodi, Baraúnas e Açu). Já a rede de supermercados Rebouças possui três lojas em Mossoró, além de uma em Açu. Vale destacar que os supermercados localizados em Mossoró atendem a toda a região polarizada pela cidade.

A grande novidade no segmento de distribuição no varejo e no atacado é a instalação da loja Atacadão, pertencente ao grupo Carrefour, empresa em franca expansão no Nordeste. Menos de um ano após a instalação do Atacadão, instalou-se também na cidade uma loja do grupo estadunidense Wal-Mart, com a 'grife' Hiper Bompreço. O ramo dos estabelecimentos popularmente chamados de supermercados se mostra disperso pela cidade. No entanto, os dois hipermercados supracitados já se instalaram na nova centralidade da cidade.

Fruto também das transformações no âmbito da troca de mercadorias no varejo, Mossoró teve seu primeiro shopping center inaugurado em julho de 2007. Até então, o Centro concentrava a quase totalidade do comércio varejista da cidade. Desde então, reorganiza parte da atividade comercial da cidade e região e concentra fatia importante do comércio de luxo, introduzindo novos hábitos e costumes, principalmente da elite local, atendendo aos padrões do consumo de massa. Assim, é um elo importante para equiparar o consumo da cidade e região ao das grandes capitais, notadamente na aquisição de uma extensa gama de bens de consumo duráveis, como de eletrodomésticos e da moda de vestuário.

Tem à frente um grupo empresarial italiano e localiza-se numa extensão do bairro Nova Betânia, mais afastado do Centro e que concentra uma população de classe média alta. A empresa proprietária do projeto, em entrevista coletiva à imprensa por ocasião do lançamento do empreendimento (Jornal O Mossoroense, 16/fevereiro/2007), justifica a iniciativa pela renda per capita da cidade, além da localização estratégica do município no Oeste do Rio Grande do Norte. Prova disto é que o shopping center foi construído quase à margem de uma rodovia de acesso ao município, como ocorre em outras cidades de porte médio. Com o novo empreendimento chegam também algumas importantes lojas de redes nacionais, lojas de departamento, franquias de vestuário, lojas de eletrônicos e eletrodomésticos etc. Poderíamos citar a instalação da primeira loja Americanas de Mossoró, além de lojas como Marisa, Riachuelo, O Boticário, Pólo Play, Camisaria Colombo, livraria Siciliano, Sueldos, L'acqua di Fiori, entre outras. Isto para citar as conhecidas nacionalmente, pois, se considerarmos as redes com atuação regional, os exemplos se multiplicariam.

A produção moderna é dependente de grandes quantias de capital para se realizar e o dinheiro também é uma mercadoria, no período histórico atual. Isso faz com que os agentes financeiros passem a desempenhar novas funções, além do tradicional papel de captar e emprestar dinheiro, transformando-se nos reguladores das finanças a nível mundial e em instrumentos de financiamento da reorganização da produção e do espaço.

O país como um todo conheceu um processo de proliferação de agentes operadores no sistema financeiro, difundindo-se pelos mais distantes pontos do território nacional, e não foi diferente em Mossoró. Enquanto os bancos públicos, especialmente o Banco do Brasil e a Caixa Econômica Federal, desempenharam papel pioneiro financiando as obras de infra-estrutura, de habitação, da modernização da produção agrícola e industrial, os bancos privados dirigiram-se preferencialmente para as áreas mais propícias à reestruturação econômica. $\mathrm{O}$ resultado foi uma nova qualidade do espaço, condição e causa da intensificação de sua urbanização. 
Considerando o número de empresas bancárias e de agências, assim como o volume dos depósitos e fluxos de dinheiro e capital realizados, Mossoró não está entre as principais praças financeiras do país. Mas também conheceu mudanças inerentes ao sistema financeiro, enquanto agente básico para a difusão da reestruturação produtiva no setor salineiro; da mudança do sistema técnico da fruticultura; das pesquisas tecnológicas que fizeram avançar as forças produtivas em vários setores; dos sistemas de objetos associados às telecomunicações; da massificação do consumo de novos produtos e serviços com o oferecimento de crédito etc.

Dessa forma, associado à produção e ao consumo, produtivo e consumptivo, devemos destacar a difusão dos serviços inerentes ao novo nexo financeiro e à monetarização da vida social e da difusão do crédito (agências bancárias, caixas eletrônicos, corretoras etc.). Atualmente são catorze agências bancárias, distribuídas entre bancos públicos (Banco do Brasil, Caixa Econômica, Banco do Nordeste) e privados (Bradesco, HSBC e Itaú).

A reorganização econômica de Mossoró e região; suas rendas monetárias; o desenvolvimento de atividades assalariadas; a difusão do crédito como instrumento de viabilização da inserção da cidade na lógica da produção e das trocas globalizadas; a construção das infraestruturas econômicas urbanas, na qual o já extinto Banco Nacional da Habitação teve papel destacado etc., tudo isto nos faz entender a expansão e o funcionamento do sistema financeiro em Mossoró.

A regulação financeira foi importante seja coletando poupança local, seja intermediando a internalização dos capitais externos, assim como substituindo as fontes usurárias tradicionais. Dessa forma, o sistema financeiro tanto atuou como condição para a difusão dos novos padrões de produção, circulação e consumo, quanto foi uma consequência dessa mesma reestruturação econômica.

Os serviços de ensino técnico e superior, público e privado, são também importantes para observar as especificidades de Mossoró. São cinco as instituições de ensino superior, sendo três universidades, duas públicas (Ufersa - Universidade Federal Rural do Semi-Árido; UERN - Universidade Estadual do Rio Grande do Norte) e uma privada (UNP - Universidade Potiguar), e duas faculdades (Facene - Faculdade de Enfermagem Nova Esperança e Faculdade Materchristi). AUfersa é a mais antiga e consolidada instituição de ensino superior da cidade. Até muito recentemente, denominava-se ESAM e é uma das instituições de ensino de ciências agrárias mais respeitadas do país. Recebeu a atual nomenclatura a partir de sua federalização, ocorrida em 2005.

Outro serviço que vem recebendo investimentos de novos agentes econômicos é o de hospedagem. Mossoró caracteriza-se por apresentar um setor hoteleiro com poucos estabelecimentos, sem nenhum hotel de alto padrão ou de alguma rede nacional ou internacional, sendo todos os empreendimentos existentes de capital local ou, no máximo, regional. Mas, a demanda crescente por serviços de hospedagem em Mossoró já provoca reorganização no setor, sendo que, no presente, estão em construção dois novos empreendimentos, totalmente baseados nos parâmetros internacionais modernos de hospedagem executiva, ou seja, distintos dos predominantes hoje. O empreendimento mais importante pertence à multinacional do setor Accor, que possui mais de quatro mil hotéis em todo o mundo, e terá a bandeira ÍBIS.

A proliferação de serviços associados às novas formas de consumo inerentes ao lazer também se fazem presentes em Mossoró: restaurantes, bares, videolocadoras e lan houses, de forma especial, instalaram-se na cidade na última década. Cabe aqui destacar que boa parte destes fixos associados ao terciário encontra-se localizada na centralidade tradicional e que outros - ainda que dispersos - favorecem o surgimento de nova centralidade, promovendo com isso a reestruturação do espaço intra-urbano de Mossoró, os quais virão a ser discutidos no próximo tópico.

\section{PROCESSO DE ESTRUTURAÇÃO DA CIDADE E CRISE URBANA}

No sentido de apontar o quadro atual de estruturação urbana de Mossoró e seus elementos estruturantes, pretende-se neste tópico apresentar ao leitor informações que possam contribuir para a compreensão da especificidade deste processo para o caso de Mossoró. 


\section{OS ELEMENTOS ESTRUTURADORES DA CIDADE}

Entre os elementos estruturantes da cidade de Mossoró, destaque especial merece ser dado ao seu sistema viário regional, seja ele intrarregional, interligando a cidade aos municípios que compõem sua área de influência, seja interestadual, entre Mossoró e as capitais mais próximas. Sua posição, entre as regiões metropolitanas de Natal e de Fortaleza, garante para a rodovia que as interliga um papel estruturante, o qual conduz o processo de expansão da cidade.

Da mesma maneira, verificamos que algumas das antigas rotas comerciais, por onde as matérias-primas eram transportadas em estradas rudimentares, remanescem sob novas formas, tendo as mesmas influenciado fortemente a estruturação da cidade. Apesar da implantação da alça de contorno na década de 1970, que retirou das áreas centrais o grande fluxo de caminhões transportadores de sal, o centro permanece como elemento estruturante da cidade. Para tanto, contribui a reestruturação viária, com a abertura de novas vias ou a duplicação de outras, interligando a área central aos eixos viários regionais principais, como a BR 110, que atravessa o intra-urbano mossoroense de sul a norte, vinda do sertão em direção ao município de Areia Branca, e à BR 304, de oeste a leste, vinda de Fortaleza em direção a Natal.

Ao tratarmos da cidade inserida na região, é notória a relação entre a localização das principais atividades produtivas e a sua atual estrutura intraurbana. Representando mais de $95 \%$ da produção de sal, boa parte da qual escoada por caminhões provenientes de municípios situados no litoral (Grossos e Areia Branca), verifica-se a presença de estruturas de apoio logístico à circulação e à distribuição da produção, bem como atividades de beneficiamento a oeste e a noroeste da cidade, ao longo das BRs 110 e 304 (em direção a Areia Branca). Destaque deve ser dado às indústrias de materiais de construção que recentemente se implantaram no município.

Ainda que em condições precárias, essa infraestrutura de circulação atende também à produção agrícola, especialmente ao agronegócio da fruticultura implantado no espaço agrícola de Mossoró e nos municípios vizinhos situados no vale do Açu e na chapada do Apodi, expandindo-se até o Ceará, no vale do Jaguaribe. Com isso, parte dos estabelecimentos comerciais e prestadores de serviços para o agronegócio, que atendem a toda a região produtiva do agronegócio (Elias, 2011) comandada por Mossoró, vem se instalando ou mesmo alguns deslocando-se do centro para a BR 304, configurando-se em uma localização especial voltada para o agronegócio, especialmente da fruticultura tropical.

Desde a implantação da Base 35 da Petrobras, sede regional da empresa, em trecho lindeiro à Avenida Wilson Rosado, no Alto do Sumaré, em substituição às instalações provisórias no Alto de São Manoel, primeiro endereço da Petrobras no município, observa-se a concentração de empresas prestadoras de serviços terceirizados à Petrobras nas suas proximidades, definindo a saída para Natal, como o setor que agrega as atividades vinculadas ao petróleo.

Ressaltamos, ainda, que a leitura da cidade, a partir de sua compartimentação em zonas que agregam bairros, segundo eixos viários e atividades produtivas definidoras de usos nas vizinhanças, permite antever a diferenciação social com que o espaço urbano vem sendo produzido, visualizando-se, por um lado, diversas frentes periféricas que tendem a abrigar os grupos socialmente excluídos, e por outro, a indicação de um vetor de expansão de empreendimentos de incorporadores imobiliários voltado às camadas mais abastadas. A implantação dos empreendimentos residenciais associados ao Programa Minha Minha Vida corroboram com essa lógica, identificando-se clara diferenciação na localização dos conjuntos pra famílias de 0 a 3 salários mínimos frente àqueles promovidos para outros com maior poder aquisitivo.

Os valores representados pelo consumo de bens materiais e imateriais, assim como a reestruturação da cidade vêm se instalando na vida dos indivíduos e da coletividade mossoroense. No jogo do mercado, as áreas onde a população possui uma renda mais elevada apresentam-se como prioritárias para o desenvolvimento de certos setores da produção não material, agravando os desequilíbrios intraurbanos e regionais, através da expansão do comércio e dos serviços. Da mesma 
forma, as áreas de implantação dos equipamentos e infraestruturas modernas passam a ser áreas de incremento da especulação imobiliária, com a implantação de novos produtos imobiliários, introduzindo práticas inerentes ao mercado imobiliário até então pouco comuns na cidade, com o consequente crescimento do preço da terra urbana.

A estrutura fundiária rural de Mossoró, assim como de todo o entorno, até então com grandes propriedades, somada aos interesses de natureza fundiária e imobiliária, têm contribuído para o crescimento do tamanho da cidade, que se espraia com velocidade, nas últimas duas décadas. $\mathrm{O}$ maior exemplo é a nova frente de expansão do mercado imobiliário com a concentração de importantes empreendimentos desde a BR 304 em direção a oeste do centro tradicional, na mesma área onde foi implantado o shopping center.

A situação geográfica de Mossoró parece ser, também, uma explicação importante para o espraiamento da cidade, uma vez que não há nas proximidades nenhuma outra cidade de mesmo porte, estendendo não só a cidade como também os papéis regionais que desempenha. A análise da rede urbana a qual pertence Mossoró não deixa dúvidas sobre isto.

\section{REESTRUTURAÇÃO DO CENTRO}

Como ocorre na cidade capitalista, o espaço é organizado de forma fragmentada, fazendo-se a opção por realizar os investimentos de forma seletiva, ficando o restante da cidade à margem das grandes inversões públicas e privadas, denotando a natureza da reestruturação da cidade, marcada pela ampliação das desigualdades socioespaciais.

No caso de Mossoró, a área central da cidade considerada pela intervenção urbanística, que era anteriormente ocupada pela via férrea, foi escolhida para receber os portentosos investimentos públicos inerentes à reestruturação urbana. Nesse caminho, a Prefeitura fez a opção pela realização de vultosos investimentos para a construção de alguns equipamentos para receber grandes eventos, reunindo num só conjunto: museu, teatro, memorial, parque infantil, praça de alimentação, entre outros. A construção desses equipamentos contou com investimentos públicos e privados, resultando na reestruturação e em nova dinâmica da cidade de Mossoró, trazendo novo significado para essa área. (Figura 2)
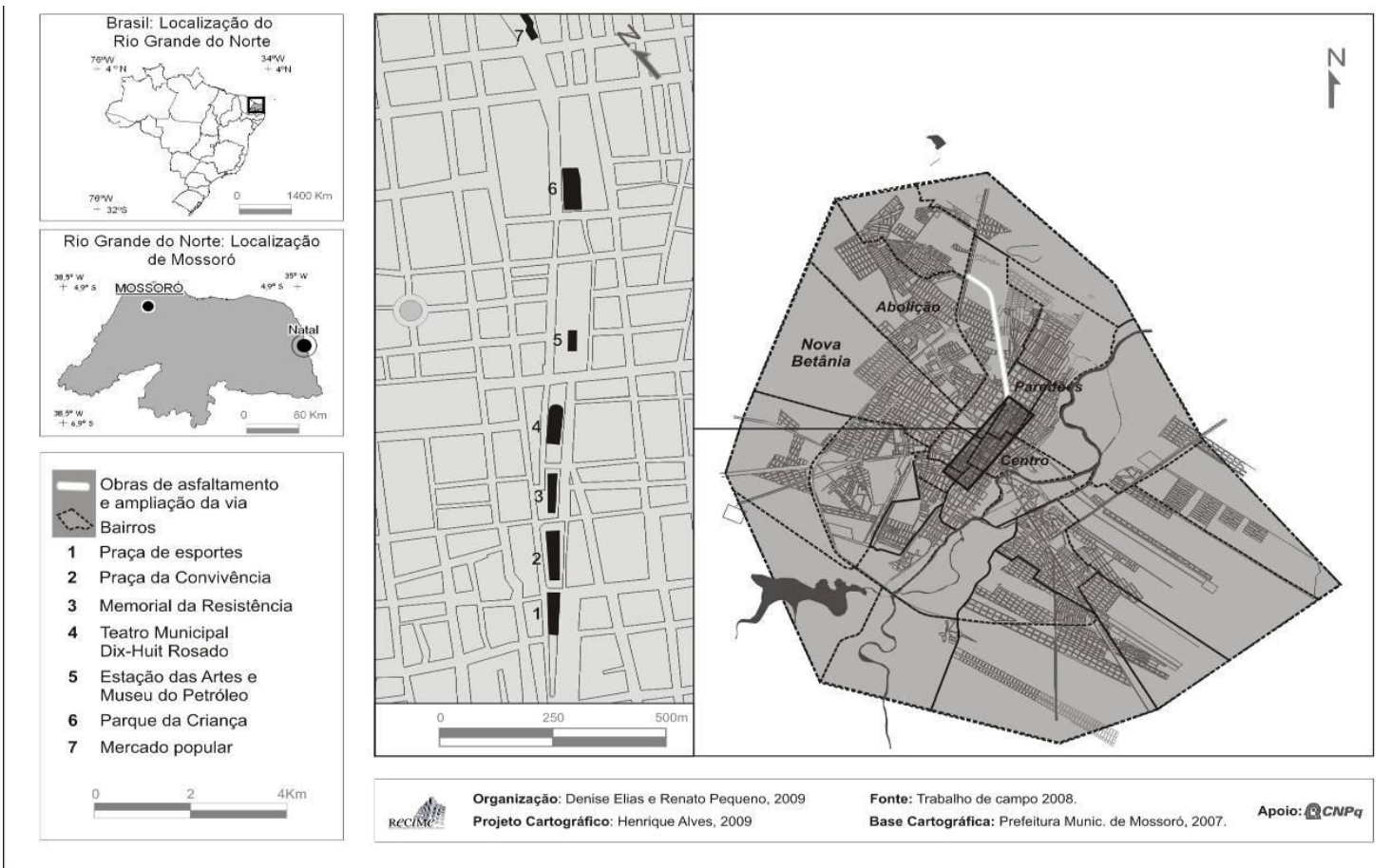

Figura 2 - Mossoró. Equipamentos da Avenida Rio Branco. 2008. 
Configura-se, claramente, um processo de 'embelezamento' de seus espaços públicos, através da recuperação de alguns equipamentos socioculturais e mesmo da implantação de novos edifícios e equipamentos para realização de eventos. É neles que ocorrem as principais festas sobre as quais recaem fortes sistemas de marketing, realizados pelo executivo local, buscando transformar algumas das festas tradicionais da região em produtos a serem consumidos por parcelas crescentes da população local e regional.

Dessa forma, numa sociedade na qual a cultura adquire valor de mercado, o processo de espetacularização de algumas festas tradicionais à Mossoró e região vem tendo forte rebatimento na reorganização do espaço urbano (BEZERRA, 2007). Algumas manifestações são verdadeiros signos da cultura do semiárido nordestino apropriados pela racionalidade empresarial inerente ao atual sistema temporal. Envolve toda a complexa discussão sobre a cultura de massa, associada à unificação do território e do mercado para a expansão da sociabilidade urbana.

No que tange diretamente aos objetivos da pesquisa realizada, visando ao levantamento dos espaços fixos e transitórios para a realização de grandes eventos, destacaríamos seis espaços: o Teatro Municipal Dix-Huit Rosado Maia; o Centro de Exposições e Eventos de Mossoró (Expocenter); a Avenida Cultural Nestor Saboya; o Corredor Cultural de Mossoró (Av. Rio Branco); o Ginásio Poliesportivo Dr. Pedro Ciarlini Neto e o Estádio de Futebol Leonardo Nogueira.

\section{NOVA CENTRALIDADE}

Apesar da forte centralidade do centro principal, já se configura uma nova centralidade a partir de novos produtos imobiliários antes não existentes na cidade, tal como o shopping center. Ambas as centralidades, antiga e a que se configura, agregam atividades do terciário, enquanto que outras tendem a se dispersar, seja para atendimento às demandas locais, como os supermercados, seja pela preexistência de equipamentos.

No caso da instalação do shopping center, apesar do pouco tempo de sua implantação (2007), ele está funcionando como um verdadeiro extensor urbano. Instalado em área até então pouco ocupada, com terras com preços bastante baixos, desde o início das obras, alguns outros importantes empreendimentos já se instalaram no 'rastro' de sua construção. Dentre os mais importantes exemplos, citaríamos a instalação de uma universidade privada, a UNP ('filial' de unidade existente na capital do Estado, Natal); um condomínio fechado de casas; uma loja do Atacadão (grupo Carrefour); uma loja de fast food com cerca de 1,2 mil $\mathrm{m}^{2}$ de área construída etc. Destacaríamos o condomínio residencial do grupo Alphaville Urbanismo S/A, de São Paulo, que está com projeto em andamento para construir condomínio com 537 lotes. Tudo isso na mesma avenida do shopping center ou nas suas imediações tem provocado um intenso processo de especulação imobiliária, fazendo com que o preço dos lotes se multiplique muitas vezes em pouco tempo.

O depoimento de uma moradora dá-nos ideia da intensidade da especulação atual. Ela cita que comprou um terreno em 2001 pelo preço de R $\$ 1.200,00$ e passados sete anos, era possível vender o mesmo pelo preço de $\mathrm{R} \$ 40.000,00$. Ainda, segundo a mesma moradora, uma imobiliária que está comercializando lotes no bairro, estava pedindo então R\$50.000,00 pelo lote de $12 \mathrm{~m} \mathrm{X} 30$ $\mathrm{m}$, isto para os terrenos mais distantes do shopping center, sendo que para os próximos os preços estão ainda mais elevados (entrevista realizada por Rodrigo Góis, em março de 2008).

Dessa forma, já é possível observar a configuração de uma nova centralidade. A facilidade de acesso através de vias regionais, como a BR 304, também confirma essa tese, visto que as duas centralidades quando associadas, assumem um caráter regional, atendendo a demandas de outros vários municípios vizinhos. Nessas centralidades concentra-se parte significativa dos investimentos públicos e privados, dos recursos financeiros de várias magnitudes e naturezas, tais como para implantação dos sistemas técnicos inerentes às telecomunicações, aos transportes, à eletrificação, dando maior fluidez a essas partes da cidade, requisito básico para a implantação das empresas. Toda essa reestruturação da cidade explica também o significativo crescimento do ramo da construção civil. 
A figura 3 apresenta as duas centralidades presentes na atual estrutura intra-urbana de Mossoró, destacando-se a presença do processo de verticalização ao longo do mesmo.
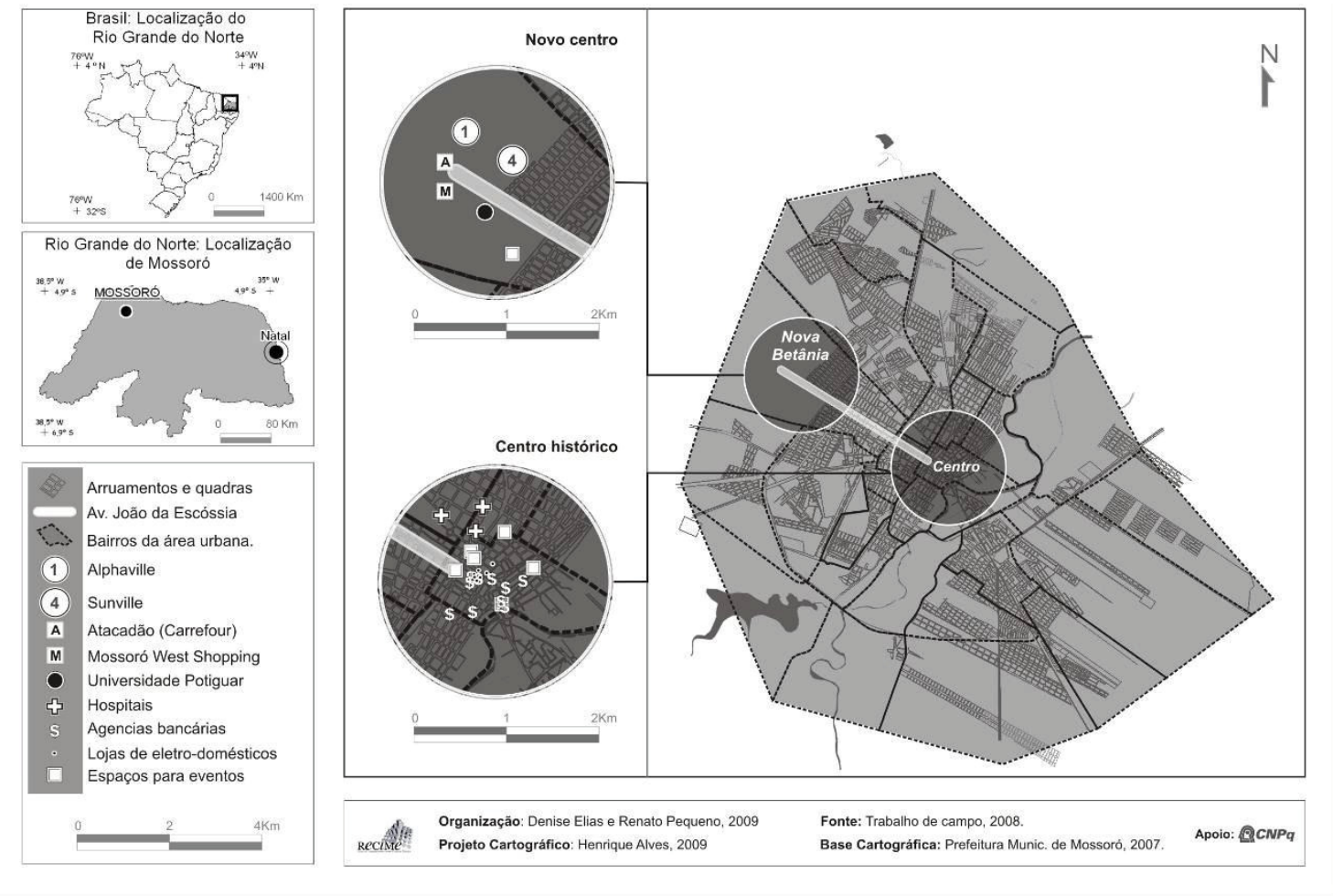

Figura 3 - Mossoró. Centro histórico e novo centro nucleado pelo Shopping Center.

\section{EVIDÊNCIAS DE CRISE URBANA}

Em Mossoró e região, campo e cidade têm sido modificados ao sabor de uma racionalidade excludente. Ao lado da descentralização espacial de uma série de atividades que chegam ao município, temos processos crescentes de centralização e concentração da riqueza. Concomitantemente, rapidamente e de forma complexa, o jogo do mercado passou a ser predominante, difundindo a moral representada pelo consumo de bens materiais e imateriais. Da mesma forma, a entrada de capitais externos vem gerando novas lógicas de localização das atividades comerciais e de serviços, redefinindo a centralidade de Mossoró.

Tais aspectos têm contribuído para o agravamento das desigualdades socioespaciais e desequilíbrios intra-regionais. No presente texto, não será possível explanar especificamente sobre as desigualdades socioespaciais de Mossoró. Para maiores informações sobre o tema, pode ser visto Elias e Pequeno (2010, capítulo 5). Nesse capítulo tivemos como principal objetivo apresentar algumas das evidências já constatadas a partir de um dos temas da pesquisa, qual seja, o do aprofundamento das desigualdades socioespaciais no espaço urbano, tendo na moradia a variável principal escolhida para análise, apresentando um conjunto de processos adjacentes. São apresentados alguns elementos metodológicos utilizados, visando contribuir com a formulação de uma síntese que possa nortear as similaridades entre as realidades percebidas nos diferentes municípios analisados na pesquisa como um todo. São discutidos, também, os principais processos constatados, objetivando-se sistematizar o conjunto de pressões que levam à ocorrência dos mesmos, assim como os impactos derivados e as possíveis respostas até aqui propostas pelos diferentes agentes produtores do espaço. Apesar de reconhecermos as interseções derivadas de associações entre os diferentes agentes produtores do espaço urbano, destacamos a cidade das políticas públicas, a cidade espontânea e informal e a cidade do mercado imobiliário. 
Essas desigualdades, associadas ao rápido crescimento demográfico e de reestruturação territorial pelo qual tem passado a sede do município, têm se refletido na forma de organização da cidade, que passa a apresentar e reproduzir alguns dos problemas urbanos presentes nas cidades maiores, uma vez que ocorrem sem o devido acompanhamento de uma política de desenvolvimento urbano eficaz, pautada em instrumentos de planejamento urbano adequados ao controle da especulação imobiliária, resultando no crescimento das irregularidades fundiárias e numa série de conflitos de uso e ocupação do solo, além de problemas de circulação e mobilidade.

Entre esses problemas, poderíamos destacar: acessibilidade desigual aos equipamentos e às redes de infraestrutura; insuficiência de equipamentos (creches, escolas, postos de saúde) nas áreas habitadas pela população de menor renda; intensificação da favelização nos espaços destinados a usos institucionais e áreas verdes; surgimento de áreas em situação de risco; presença de vazios urbanos com consequente especulação imobiliária; loteamentos periféricos clandestinos desprovidos de infraestrutura; congestionamento nas áreas centrais por movimentação de carga e descarga; pólos geradores de tráfego sem capacidade de escoamento, entre outros

Tudo isso repercute na atração de mão de obra, especializada ou não, contribuindo sobremaneira para o crescimento urbano desse município, onde passam a emergir além de formas precárias de moradia associadas à carência de redes de infraestrutura urbana e equipamentos sociais, uma série de conflitos de uso e ocupação do solo. Da mesma maneira, sobressaem os espaços de riqueza na cidade, compostos por condomínios verticais e horizontais, assim como por loteamentos fechados recém-lançados, estabelecendo um quadro de segregação socioespacial na cidade. Ainda que denominado como habitação econômica, observa-se também a emergência de condomínios de menor porte em bairros providos de infraestrutura urbana, atendendo à demanda com renda entre 3 e 10 salários mínimos graças aos recursos disponibilizados pelo Programa Minha Casa Minha Vida. Cabe ressaltar que o rápido crescimento demográfico tem feito com que o quadro de desigualdades se torne cada vez mais evidente.

Acreditamos mesmo que podemos falar na existência de diferentes 'cidades' que se superpõem no intraurbano de Mossoró, distinguindo-as da seguinte maneira: a) a cidade das políticas públicas, onde prevalece a localização de conjuntos habitacionais de interesse social; b) a cidade espontânea e informal, correspondente às formas de moradia predominantemente precárias; c) a cidade do mercado imobiliário, agrupando as áreas sob influência do mercado imobiliário, voltadas para aqueles com maior poder aquisitivo. Reconhecemos claramente, no entanto, a presença de interseções derivadas de associações entre os diferentes agentes produtores do espaço, nem sempre explícitas, as quais se tornam, por vezes, visíveis através da análise dos instrumentos de planejamento e gestão do solo urbano, formulados sob a égide do poder local.

Buscando compreender a urbanização de Mossoró, foram identificados vários processos que se repetem em diversas outras partes do país, apesar da diversidade da realidade econômica, socioambiental e cultural. Esses processos encontram-se diretamente relacionados ao rápido crescimento demográfico e de reestruturação territorial pelo qual tem passado a sede do município. Deflagra-se desordenado crescimento urbano, expandindo-se a cidade. Passa, então, a ocorrer uma série de problemas atrelados à circulação e à mobilidade urbana e regional, atingindo tanto a área central da cidade como a periferia, os espaços de transição e as localidades rurais.

Como evidenciado, da acessibilidade desigual aos equipamentos sociais e às redes de infraestrutura entre as populações da cidade e do campo, assim como da centralização das instituições públicas e dos serviços no município de Mossoró, emergem diversas questões associadas à forma desigual como se dá o acesso aos benefícios trazidos pela urbanização, assim como aos conflitos e incompatibilidades de uso e ocupação do território. Isso leva ao surgimento de marcas de degradação ambiental comprometedoras das condições de habitabilidade nas diferentes escalas. 


\section{CONSIDERAÇÕES FINAIS}

Considerando as análises realizadas para os diferentes temas da pesquisa, notadamente a difusão do agronegócio; a descentralização da produção industrial; a difusão do comércio e dos serviços especializados; e o aprofundamento das desigualdades socioespaciais, é possível reconhecer um conjunto de aspectos, os quais podem ser mencionados como singularidades, desse peculiar espaço não metropolitano organizado por Mossoró, enquanto cidade média.

No que tange aos principais papéis que desempenha a expansão da produção e do consumo de produtos modernos e sofisticados, inerente às novas formas de produção, distribuição e consumo evidenciam-se mudanças no espaço urbano, assim como seu reforço enquanto cidade que polariza um mercado regional.

Parece-nos então que, em termos de funções regionais, Mossoró exerce alguns papéis clássicos de cidade média, para atividades como ensino superior, saúde, comércios e serviços especializados. Da mesma forma, desempenha um papel importante no oferecimento de parte das demandas das principais atividades produtivas que se dão na sua área de influência, compondo um conjunto urbano e econômico maior. Vale destacar que esses papéis regionais se combinam com interesses e comandos advindos de outras escalas. Poderíamos classificá-la, então, no bloco de cidades já consolidadas como cidades médias.

A chegada das médias e grandes empresas nacionais e multinacionais na área sob influência de Mossoró aumenta a especialização da produção e as trocas. Da mesma forma, reforçam-se as determinações exógenas à cidade e à região, especialmente no tocante aos mercados consumidores cada vez mais longínquos e competitivos, uma vez que parte do objetivo principal da produção da região são os mercados externos.

Fato semelhante ocorre em relação aos preços, internacionais e nacionais, comandados pelas principais bolsas de mercadorias do mundo, sobre os quais não há controle local. Também aumentam as distâncias entre os produtores e os centros de comando e de pesquisa. Exemplos podem ser dados para as principais atividades econômicas, algumas com produções bastante verticalizadas, com pouca interação com os poderes locais. Algumas praticamente ignoram por completo as legislações estaduais e municipais, como é muito frequente com a legislação ambiental e trabalhista no caso das empresas agrícolas da fruticultura.

O que vemos é um choque permanente entre os elementos dos diferentes pares dialéticos para a análise da produção e do espaço, tais como as relações estabelecidas entre o público e o privado; entre as novas relações de produção e de trabalho e as pré-existentes, ainda pouco monetarizadas em algumas atividades; a cultura de subsistência do semiárido e a cultura das multinacionais; a solidariedade orgânica, localmente tecida há séculos, e a solidariedade organizacional difundida com a chegada dos grandes capitais etc.

Diríamos, então, que o que temos não é a predominância nem do novo, nem do velho, nem das rupturas, nem das permanências, mas uma convivência permanente entre ambos, ora sobressaindo um, ora outro. Isso pode ser observado em vários aspectos da vida de relações, tais como nas de trabalho, que combinam formas assalariadas com formas rentistas, como ocorre na produção de frutas.

A chegada de um grande número de empresas acirrou a divisão social e territorial do trabalho, com a refuncionalização do espaço agrícola e urbano, difundindo-se especializações produtivas, denotando-se, então, uma seletividade na organização da produção e do espaço. Novos agentes econômicos surgem para atender às demandas produtivas do petróleo, da fruticultura e do sal e a ampliação e diversificação do setor de serviços em geral, com uma readequação no setor atacadista e no varejo. Da mesma forma, muitas novas atividades vêm buscando se expandir, como a de turismo de eventos e negócios.

As características do crescimento econômico em Mossoró nos levam a afirmar que se formou aí um espaço "dócil" às novas formas de regulação, aberto à realização da racionalidade vigente no período histórico atual, constituindo-se uma região do fazer (SANTOS, 1996), mas com pouca 
ou nenhuma possibilidade de reger os processos hegemônicos. Mas, destacamos, não se trata aqui de uma situação clássica de enclave, vistas as horizontalidades e verticalidades construídas, assim como sua participação numa cooperação globalizada.

Muito embora Mossoró não tenha o poder de comando sobre as suas três principais atividades, a cidade funciona como uma espécie de ponto de interseção para a solidariedade organizacional entre as empresas hegemônicas atuando na região sob sua influência, oferecendo os meios para a coesão entre as mesmas. Dessa forma, a cidade é organizada para servir aos interesses das grandes empresas do circuito superior da economia do agronegócio da fruticultura, da extração do sal e do petróleo, que se apresentam enquanto hegemônicas na organização do espaço urbano de Mossoró e região.

Enquanto mera região do fazer, os circuitos espaciais de produção e os círculos de cooperação das empresas associadas as três principais atividades se realizam em várias outras partes do mundo, significando que a quantidade de relações, materializadas em fluxos materiais e imateriais, apresenta crescimento constante, evidenciando que a articulação entre diferentes escalas geográficas é muito forte.

Isso reforça o papel de Mossoró enquanto mera região do fazer e não uma região do mandar, do reger. Teríamos, assim, uma região alienada, uma vez que não consegue ter ingerência sobre os processos que nela ocorrem. Com a dispersão espacial da produção, passa a ter possibilidade de executar, mas continua sem poder para decidir os rumos de seu desenvolvimento.

Em Mossoró e região, campo e cidade foram modificados ao sabor de uma racionalidade excludente. Ao lado da descentralização espacial de uma série de atividades que chegam, temos processos crescentes de centralização e concentração da riqueza. Concomitantemente, rapidamente e de forma complexa, o jogo do mercado passou a ser predominante, difundindo a moral representada pelo consumo de bens materiais e imateriais. Tais aspectos têm contribuído para o agravamento das desigualdades socioespaciais e desequilíbrios regionais.

A reprodução de uma modernização conservadora da economia, que já mostrou seus efeitos danosos por todo o País, tem aumentado, de fato, a produção e a produtividade, ampliando a competitividade do setor empresarial atuante em Mossoró e região. Mas a grande maioria da população encontra-se alijada dessas benesses, elevando-se os níveis de pobreza, seja na cidade, seja no campo. Dessa forma, se o crescimento econômico é um resultado efetivo da apropriação de Mossoró e região pelos grandes capitais, o mesmo se pode dizer dos impactos negativos, sejam sociais, territoriais ou ambientais, acentuando-se as históricas desigualdades socioespaciais.

Compreender os fixos e os fluxos, os sistemas de objetos e os sistemas de ação das principais empresas territorializadas em Mossoró e região - principalmente as associadas ao circuito superior (SANTOS, 1979) da economia urbana e agrícola - com vistas a entender seus circuitos espaciais de produção e os seus círculos de cooperação, é um exercício de análise que permite a síntese das estratégias de ação dos grandes conglomerados e das empresas em geral atuantes na cidade e região, assim como do território resultante desses processos, ou seja, das novas especializações territoriais produtivas, assim como de toda sorte de desigualdades socioespaciais.

Essas constatações são importantes, inclusive, para pensar nas formas de expansão da urbanização brasileira nas últimas três décadas, pois evidencia a associação direta de grandes capitais nacionais e multinacionais com capitais locais e regionais em diferentes lugares do país e mudam, radicalmente, as antigas articulações da rede urbana, seja regional seja nacional.

\section{AGRADECIMENTOS}

O presente texto constitui parte de pesquisa maior, realizada em rede, intitulada "Cidades médias brasileiras: agentes econômicos, reestruturação urbana e regional", coordenada por Maria Encarnação Sposito (Unesp/PP) e Denise Elias (UECE), de 2006 a 2009, que contou com o apoio do CNPq. 


\section{REFERÊNCIA BIBLIOGRÁFICA}

ANDRADE, Manuel Correia. O território do sal. A exploração do sal marinho e a produção do espaço geográfico no Rio Grande do Norte. Natal: CCHLA/ UFRN, 1995. Coleção Mossoroense. V. 848.

ARAÚJO, T. B.. Herança de diferenciação e futuro de fragmentação. Estudos Avançados (IEA/USP), São Paulo, v. 2, n. 29, p. 7-36, 1997.

BEZERRA, A. C. A. Festa e Identidade: a busca da diferença para o mercado de cidades. In: ARAÚJO, F. G. B.; HAESBAERTH, R. (Org.). Identidades e territórios. Rio de Janeiro: Access, 2007.

CARLOS, A. F. A. A questão da cidade e do campo. Mercator, Fortaleza, v. 5, p. 8-13, 2004.

CORREAA, Roberto Lobato. O Construindo o conceito de cidade média. In: SPOSITO, Maria Encarnação B. (Org.). Cidades médias: espaços em transição. São Paulo: Expressão Popular, 2007. P. 23-34.

EGLER, Cláudio Antônio G.; PIRES DO RIO, Gisela A. Territórios do Petróleo no Brasil: redes globais e governança local. In: COLLOQUE INTERNATIONAL "LES INTEGRATIONS REGIONALES : QUELLES DYNAMIQUES TRANSFRONTALIĖRES ET TRANSNATIONALES ? LES ENSEIGNEMENTS DU BASSIN DE LA PLATA DANS LE MERCOSUD”, 2004, Toulouse. Actes du Colo que... Université de Toulouse 2 - Le Mirail, 2004. v. 1. P. 72-86.

INSTITUTO BRASILEIRO DE GEOGRAFIA E ESTATÍSTICA. Regiões de influências das cidades 2007 (Regic). RJ: Ministério do Planejamento, Orçamento e Gestão, IBGE, 2008.

ELIAS, D. Globalização e Agricultura. SP: Edusp, 2003.

ELIAS, D. Redes agroindustriais e produção do espaço urbano no Brasil agrícola. In: SILVA J. B.; LIMA,L. C.; ELIAS, D. (Org.). Panorama da Geografia Brasileira. São Paulo: Annablume, 2006. p. 221-238.

ELIAS, D. Agricultura e produção dos espaços urbanos não metropolitanos: notas teórico-metodológicas. In: SPOSITO, M. E. (org.). Cidades médias. São Paulo: Expressão Popular, 2007. 632 p. (p. 113- 138).

ELIAS, Denise. Redes agroindustriais e urbanização dispersa no Brasil. Scripta Nova, v. XII, p. 74-96, 2008.

ELIAS, D. Agronegócio e Novas Regionalizações no Brasil. Revista Brasileira de Estudos Urbanos e Regionais (Anpur), v.13, n.2, novembro 2011, p.153-167.

ELIAS, D.; PEQUENO, R. (Orgs.). Difusão do agronegócio e novas dinâmicas socioespaciais. Fortaleza: BNB, 2006.

ELIAS, D.; PEQUENO, R. Mossoró: o novo espaço da produção globalizada e aprofundamento das desigualdades socioespaciais. In: SPOSITO, M. E; ELIAS, D; SOARES, B. R. (Orgs.). Agentes Econômicos, reestruturação urbana e regional: Passo Fundo e Mossoró. SP: Expressão Popular, 2010. p. 101-283.

ELIAS, Denise; PEQUENO, Renato Tendências da urbanização e os espaços urbanos não metropolitanos. Cadernos Metrópole, São Paulo, v.12, n.24, PP.441-465, jul/dez, 2010.

FELIPE, José L. A. A (re)invenção do lugar: os Rosados e o "país de Mossoró". João Pessoa: Grafset, 2001. PINHEIRO, K. L. C. B. O Processo de urbanização da Cidade de Mossoró. 2006. Dissertação (Mestrado) - Universidade Federal do Rio Grande do Norte, Natal.

PREFEITURA MUNICIPAL DE MOSSORÓ. Plano Diretor de Organização do Espaço Urbano. Mossoró: PMM, 1974.

PREFEITURA MUNICIPAL DE MOSSORÓ. Relatório de Diagnóstico do Município de Mossoró. Mossoró: PMM, 2005.

PREFEITURA MUNICIPAL DE MOSSORÓ. Plano Diretor de Mossoró. Mossoró: PMM, 2006.

SANTOS, Milton. O espaço dividido. Rio de Janeiro: Francisco Alves, 1979.

SANTOS, Milton. Espaço e método. São Paulo: Nobel, 1985.

SANTOS, Milton. Metamorfoses do espaço habitado. São Paulo: Hucitec, 1988.

SANTOS, Milton. A urbanização brasileira. São Paulo: Hucitec, 1993.

SANTOS, Milton. A natureza do espaço. São Paulo: Hucitec, 1996.

Trabalho enviado em maio de 2012

Trabalho aceito em junho de 2012 